\title{
Short communication: Effect of cross ventilation with or without evaporative pads on core body temperature and resting time of lactating cows
}

\author{
J. F. Smith, ${ }^{* 1}$ B. J. Bradford,† J. P. Harner, † J. C. Potts, † J. D. Allen, $\ddagger$ M. W. Overton,§ X. A. Ortiz, ${ }^{*}$ \\ and R. J. Collier*2 \\ *School of Animal and Comparative Biomedical Sciences, University of Arizona, Tucson 85719 \\ †Department of Animal Sciences and Industry, Kansas State University, Manhattan 66502 \\ ‡Department of Agricultural Sciences, Northwest Missouri State University, Maryville 64468 \\ §Department of Population Health, University of Georgia, Athens 30602
}

\section{ABSTRACT}

A trial was performed to assess the effect of evaporative pads on core body temperature (CBT) and lying behavior of lactating Holstein cows housed in crossventilated freestall facilities in a humid environment. This trial was undertaken in 2 barns equipped with (EP) or without (NP) evaporative pads. Each facility had 4 pens, 1 baffle/pen, and a nominal width of 122 $\mathrm{m}$. Stocking density was higher (123.4 vs. $113.1 \%)$ and freestalls were slightly shorter (2.3 vs. $2.4 \mathrm{~m})$ and narrower (1.16 vs. $1.21 \mathrm{~m}$ ) in EP compared with NP barns. In each pen, lying behavior of 20 cows was monitored using electronic data loggers that recorded at 1-min intervals. A subset $(\mathrm{n}=14)$ of these cows within each pen were also fitted with temperature loggers attached to blank controlled intravaginal drug release devices to determine CBT every 5 min. Ambient conditions were collected every 15 min. Individual cow lying duration and lying bouts were assessed for each cow, as well as time spent standing and CBT within the following categories: $\mathrm{CBT}<38.6^{\circ} \mathrm{C}$, and $\mathrm{CBT}>38.6,>38.9,>39.2$, $>39.4$, and $>39.7^{\circ} \mathrm{C}$. These variables were analyzed using pen as the experimental unit, with cow and day as additional random effects. The average maximum ambient conditions over the $9 \mathrm{~d}$ were $25^{\circ} \mathrm{C}$ and $78.74 \%$ relative humidity. No differences were observed in lying duration and number of lying bouts over the 9-d period, with overall means of $696 \pm 31 \mathrm{~min} / \mathrm{d}$ and 12.6 \pm 0.5 bouts $/ \mathrm{d}$. The EP cows spent $170 \mathrm{~min} / \mathrm{d}$ longer with a $\mathrm{CBT}<38.6^{\circ} \mathrm{C}$ and $107 \mathrm{~min} / \mathrm{d}$ less with $\mathrm{CBT}$ $>39.2^{\circ} \mathrm{C}$ than did NP cows. Cooling with evaporative pads tended to increase time spent lying with a CBT

Received March 25, 2015.

Accepted September 20, 2015.

${ }^{1}$ Deceased.

${ }^{2}$ Corresponding author: rcollier@ag.arizona.edu $>8.6^{\circ} \mathrm{C}$ and lying bouts/d for EP cows versus NP cows. Results from this trial show that even under mild heat stress, evaporative cooling in cross-ventilated facilities can decrease CBT and tended to increase lying time.

Key words: evaporative cooling, heat stress, lying behavior

\section{Short Communication}

Heat stress has very broad effects on animal behavior and physiology (Collier et al., 2006) and, in turn, dramatically affects growth, reproduction, and lactation. Heat stress is estimated to have a cost of $\$ 89.01$ per cow per year (Scharf et al., 2014) and a total annual cost to the US dairy industry of nearly $\$ 897$ million (St-Pierre et al., 2003). Although great advances have been made in understanding the effects of heat stress, many of the underlying mechanisms linking heat stress to decreased health and performance remain unclear.

Lying behavior and core body temperature (CBT) play critical roles in the production potential and profitability of dairy cattle. Milk yield typically decreases by $1.8 \mathrm{~kg}$ and DMI by $1.4 \mathrm{~kg}$ for each $0.55^{\circ} \mathrm{C}$ increase in CBT (Johnson et al., 1963; Umphrey et al., 2001). Fregonesi and Leaver (2001) reported that cows deprived of adequate lying time may have reduced welfare, whereas Munksgaard and Lovendahl (1993) reported decreased growth hormone release with lying deprivation, indicating a possible role in decreased milk production. Furthermore, cows will exhibit physiological and behavioral signs of stress, including lameness, when deprived of ample lying time (Singh et al., 1993; Munksgaard and Simonsen, 1996; Cooper et al., 2008). In congruence with stress, an inverse relationship between the proportion of cows lying and ambient temperature and a positive relationship between lying time and heat stress have been reported (Overton et al., 2002; Cook et al., 2007).

Evaporative cooling systems are more effective in hot and dry regions due to the capacity of the system to 
increase the water content of the air by changing the state of water from liquid to gas through the latent heat of vaporization. However, limited information is available when using evaporative cooling systems in humid environments. Evaporative pad cooling systems have been used in humid environments to decrease the air temperature in tunnel-ventilated facilities (Liao and Chiu, 2002). On the other hand, limited information is available on the use of evaporative pads in crossventilated freestall facilities in humid environments. Therefore, our objective was to evaluate the effect of an evaporative pad cooling system on CBT and behavior of Holstein cows housed in cross-ventilated facilities in a humid environment.

A trial was conducted over $9 \mathrm{~d}$ during the summer of 2009 on a commercial dairy farm near Morris, Minnesota. The Institutional Animal Care and Use Committee at Kansas State University approved experimental procedures. Eight pens from 2 cross-ventilated facilities (4 pens/facility) were selected for the trial. One facility was equipped with evaporative pads (EP; CELdek; Munters, Mason, MI), whereas the other had no evaporative pads (NP). The evaporative pads had a depth of $150 \mathrm{~mm}$ and a width of $600 \mathrm{~mm}$. Each facility had a nominal width of $122 \mathrm{~m}$ and 1 baffle per pen. Stocking density of the freestalls was higher in the EP facility than in the NP facility (123.4 vs. 113.1\%). Freestalls were slightly shorter $(2.3 \mathrm{vs} 2.4 \mathrm{~m})$ and narrower $(1.16$ vs. $1.21 \mathrm{~m}$ ) in EP compared with NP.

One-hundred sixty (20/pen) multiparous Holstein cows (average 161 DIM, 2.91 lactations for both treatments) with mean milk production of approximately $36 \mathrm{~kg} / \mathrm{d}$ were randomly selected for the trial. Cows were allowed at least $1 \mathrm{~d}$ of acclimation before data were gathered. Because of the short duration of these experiments, milk yield of cows was not analyzed. Milking times per day were evenly distributed between treatments. Two pens in each treatment were milked twice and the other 2 pens were milked 3 times. The EP facility had exhaust fans located on either side of the holding pen that pulled cooled air from the main building; in addition, overhead sprinklers were used to soak cows while they were in the holding pen. The NP facility had a cross-ventilated holding pen with highpressure misters on one sidewall and exhaust fans on the other sidewall.

Lying behavior of selected cows was recorded using electronic data loggers (Hobo Pendant G Acceleration Data Loggers, Onset Computer Corp., Pocasset, MA) at 1-min intervals for $9 \mathrm{~d}$ to determine time spent lying and the number of lying bouts/day. The electronic data loggers were attached to the medial side of the left cannon portion of the hind leg of each cow with the $y$-axis perpendicular to the ground. Data of vertical tilt from the $y$-axis was used to determine the animal's lying position, such that readings $<60^{\circ}$ indicated the cow standing, and readings $\geq 60^{\circ}$ indicated the cow was lying down (Ito et al., 2009).

A subset of 14 cows in each pen was also fitted with intravaginal temperature loggers (Hobo U12, Onset Computer Corp.) attached to blank controlled intravaginal drug release devices (CIDR; Pfizer Animal Health, New York, NY) to monitor CBT. Measurements were obtained at 5-min intervals for $9 \mathrm{~d}$.

Outside ambient conditions were collected every 15 min on both sites using 2 data loggers (Hobo Pro H8) per site contained within separate solar radiation shields (M-RSA; Onset Computer Corp.). Loggers recorded temperature and percentage relative humidity (RH). In addition, 8 data loggers (Hobo Pro H8; Onset Computer Corp.) were placed inside the facilities (4 on the air intake side and 4 on the air exhaust side) to determine temperature and $\mathrm{RH}$ at 15 -min intervals. All data loggers were programmed and managed by a single computer, allowing for synchronization of time.

Temperature-humidity index (THI) values were calculated based on the average temperature and humidity data obtained from the weather stations and defined by the equation (Ravagnolo and Misztal, 2000)

$$
\begin{gathered}
\mathrm{THI}=[(1.8 \times \mathrm{Tdb})+32]-(0.55-0.0055 \times \mathrm{RH}) \\
\times(1.8 \times \mathrm{Tdb}-26),
\end{gathered}
$$

where $\mathrm{Tdb}=$ dry bulb temperature $\left({ }^{\circ} \mathrm{C}\right)$, and $\mathrm{RH}=$ relative humidity (\%).

Daily lying time (h/d) and frequency of lying bouts (no./d) were calculated for each cow (Ito et al., 2010). Individual cow CBT and activity data $(9 \mathrm{~d} / \mathrm{cow})$ were analyzed to determine the amount of time per when CBT was $<38.6^{\circ} \mathrm{C}$ and $>38.6^{\circ} \mathrm{C},>38.9^{\circ} \mathrm{C},>39.2^{\circ} \mathrm{C}$, $>39.4^{\circ} \mathrm{C}$, and $>39.7^{\circ} \mathrm{C}$, as well as time spent per day standing within these CBT categories. Threshold temperatures were chosen based on evidence that even mild elevation of CBT over extended periods can negatively affect animal performance (Umphrey et al., 2001).

Variables were analyzed using SAS software (SAS 9.3, SAS Institute Inc., Cary, NC) with mixed models and pen as the experimental unit, with cow and day included as additional random effects. Parity, reproductive status, and DIM were tested as covariates in each model but were determined not to contribute significantly to the prediction equation. The effect of the cooling system was declared significant at $P<0.05$, and tendencies were declared at $P<0.10$.

Average ambient conditions were mild during the trial with average maximum temperature of $25^{\circ} \mathrm{C}$, relative humidity of $78.74 \%$, and average maximum THI 


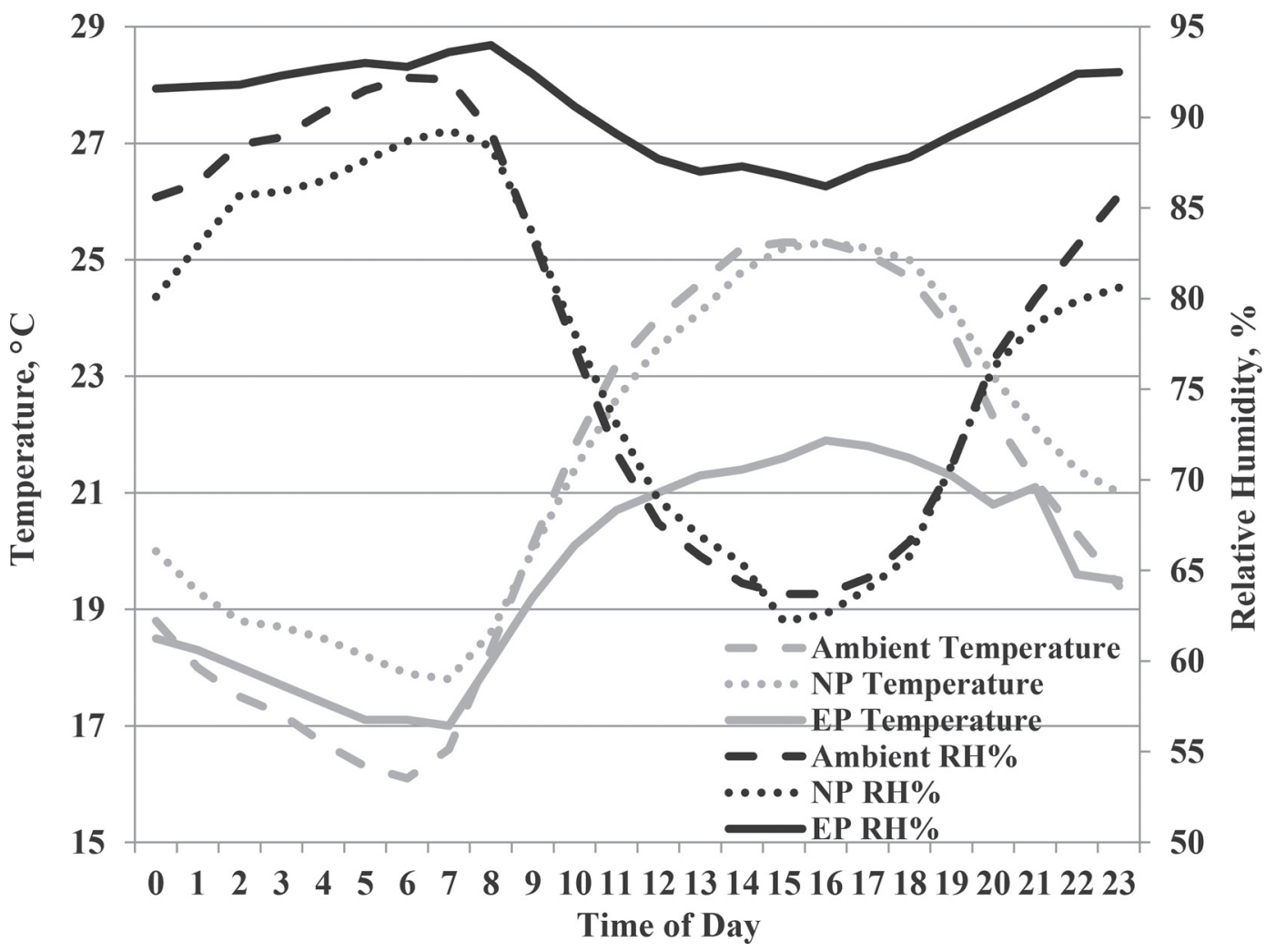

Figure 1. Ambient and indoor temperature and relative humidity values across a 24 -h period. Treatment $\left(\mathrm{SEM}=0.30^{\circ} \mathrm{C}\right.$ and $\left.0.30 \%\right)$ and treatment $\times$ hour $\left(\mathrm{SEM}=0.28^{\circ} \mathrm{C}\right.$ and $\left.1.12 \%\right)$ effects were observed for temperature $(P<0.0001)$ and relative humidity $(P<0.0001)$

of 73.7 (Figures 1 and 2). Differences between ambient temperatures were detected between the 2 barns $(19.6$ and $21.5^{\circ} \mathrm{C}$ with pads and without pads, respectively, $P$ $<0.0001$; Figure 2). Average wind speed within barn and baffle opening was $9.7 \mathrm{~km} / \mathrm{h}$ and $2.1 \mathrm{~m}$ for $\mathrm{NP}$ and $13.7 \mathrm{~km} / \mathrm{h}$ and $2 \mathrm{~m}$ for EP facilities, respectively.

Lying time and lying bouts tended $(P<0.10)$ to be $30 \mathrm{~min} / \mathrm{d}$ longer and 0.8 bouts/d more for cows treated

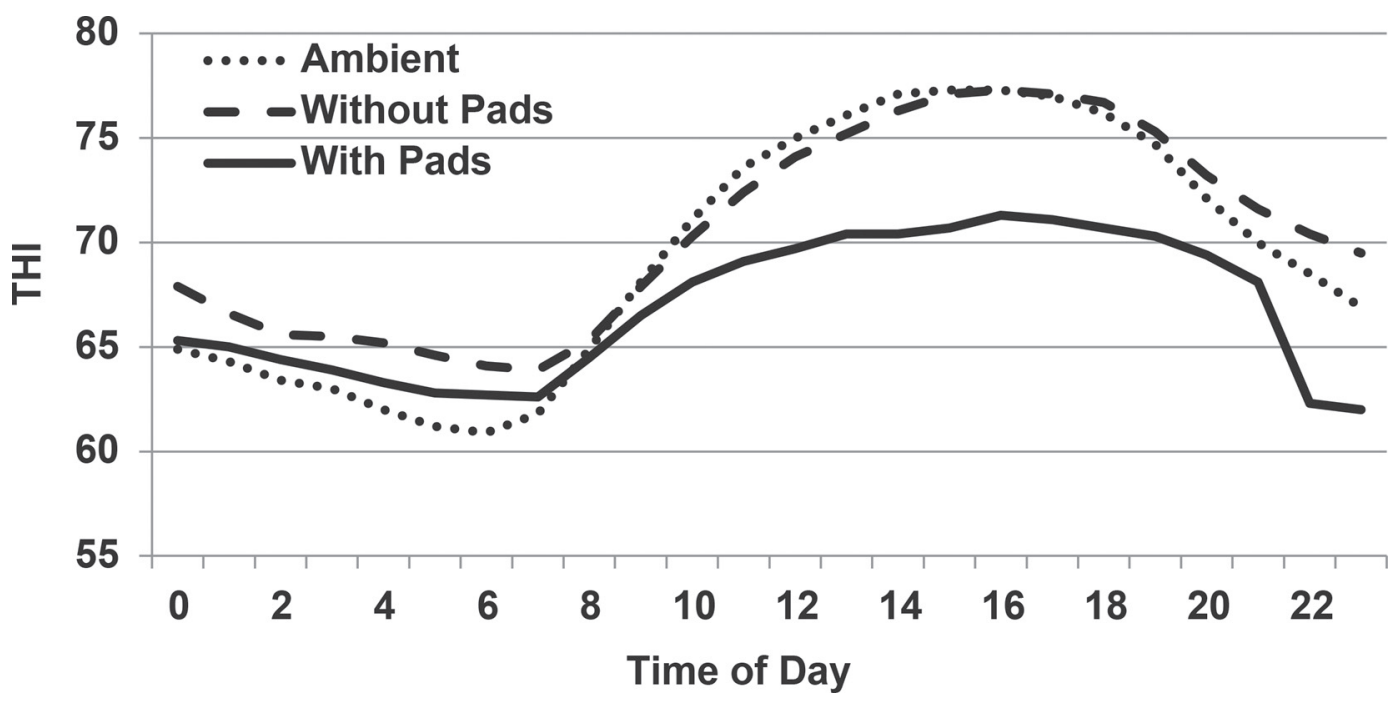

Figure 2. Ambient and indoor temperature-humidity index (THI) values across a 24-h period. Treatment $(P<0.0001 ; \mathrm{SEM}=0.30)$ and treatment $\times$ hour $(P<0.001 ; \mathrm{SEM}=0.53)$ effects were observed. 
Table 1. Effect of cross ventilation with or without evaporative pads on lying behavior of lactating dairy cows in northern Midwest United States ${ }^{1}$

\begin{tabular}{lccrc}
\hline & \multicolumn{2}{c}{ Treatment } & & \\
\cline { 2 - 3 } Item & Without pads & With pads & SEM & $P$-value \\
\hline Standing time, min/d & 762.8 & 737.1 & 10.3 & 0.08 \\
Bouts/d & 12.4 & 11.9 & 0.1 & 0.07 \\
Duration, min/bout & 76.8 & 69.9 & 2.5 & 0.07 \\
Lying time, min/d & 675.1 & 702.3 & 10.4 & 0.07 \\
Bouts/d & 13.8 & 14.6 & 0.2 & 0.07 \\
Duration, min/bout & 53.8 & 57.5 & 1.0 & 0.02 \\
\hline
\end{tabular}

${ }^{1} \mathrm{n}=160 ; 20 \mathrm{cows} /$ pen; 8 pens/treatment. Nine days of data were collected.

with evaporative pads (Table 1 ). Lying bout duration was also 3.5 min longer $(P<0.05)$ for cows with evaporative pads. A CBT $\times$ hour effect was observed $(P<$ 0.01 ; Figure 3 ), with NP cows having greater variation and greater CBT compared with EP cows. These data coincide with categorical CBT, in which NP cows spent more time $>38.6^{\circ} \mathrm{C}$ and $>39.2^{\circ} \mathrm{C}(P<0.05)$ and spent more time $>39.4^{\circ} \mathrm{C}(P \leq 0.10)$ compared with EP cows. The NP cows also had a tendency $(P<0.10)$ to stand longer at $\mathrm{CBT}>38.6^{\circ} \mathrm{C}$ and $<39.4^{\circ} \mathrm{C}$ compared with EP cows (Table 2).

Despite the cool ambient conditions, cows without evaporative pads had elevated $\mathrm{CBT}>38.6^{\circ} \mathrm{C}$ for 2.8 more hours per day and elevated CBT $>39.2^{\circ} \mathrm{C}$ for 1.8 $\mathrm{h}$ more per day. These trends were evident even though the stocking density of the freestalls was higher in the EP facility (123.4\%) than in the NP facility (113.1\%).
The results of this study coincide with other reports using different cooling systems in a more extreme environment (Ortiz et al., 2010, 2011) and provide further evidence that evaporative cooling, even under mild heat stress conditions, reduces CBT (Igono et al., 1985).

Mean CBT for both treatments are described in Figure 3. Cows in EP showed lower CBT compared with cows in NP $\left(38.6\right.$ and $38.7^{\circ} \mathrm{C}$, respectively; $P<$ 0.05 , Figure 3). Core body temperature across a $24-\mathrm{h}$ period illustrated a greater range $\left(0.25^{\circ} \mathrm{C}\right)$ in the NP cows, whereas EP cows were kept within a tighter CBT range of $0.15^{\circ} \mathrm{C}$ (Figure 3). In addition, EP cows were kept consistently nearer or below the CBT benchmark of $38.6^{\circ} \mathrm{C}$, a threshold temperature that cattle exhibit in thermoneutral conditions (Dukes, 1947); as CBT increases above this threshold, loss of potential productivity can be experienced (Johnson et al., 1963).

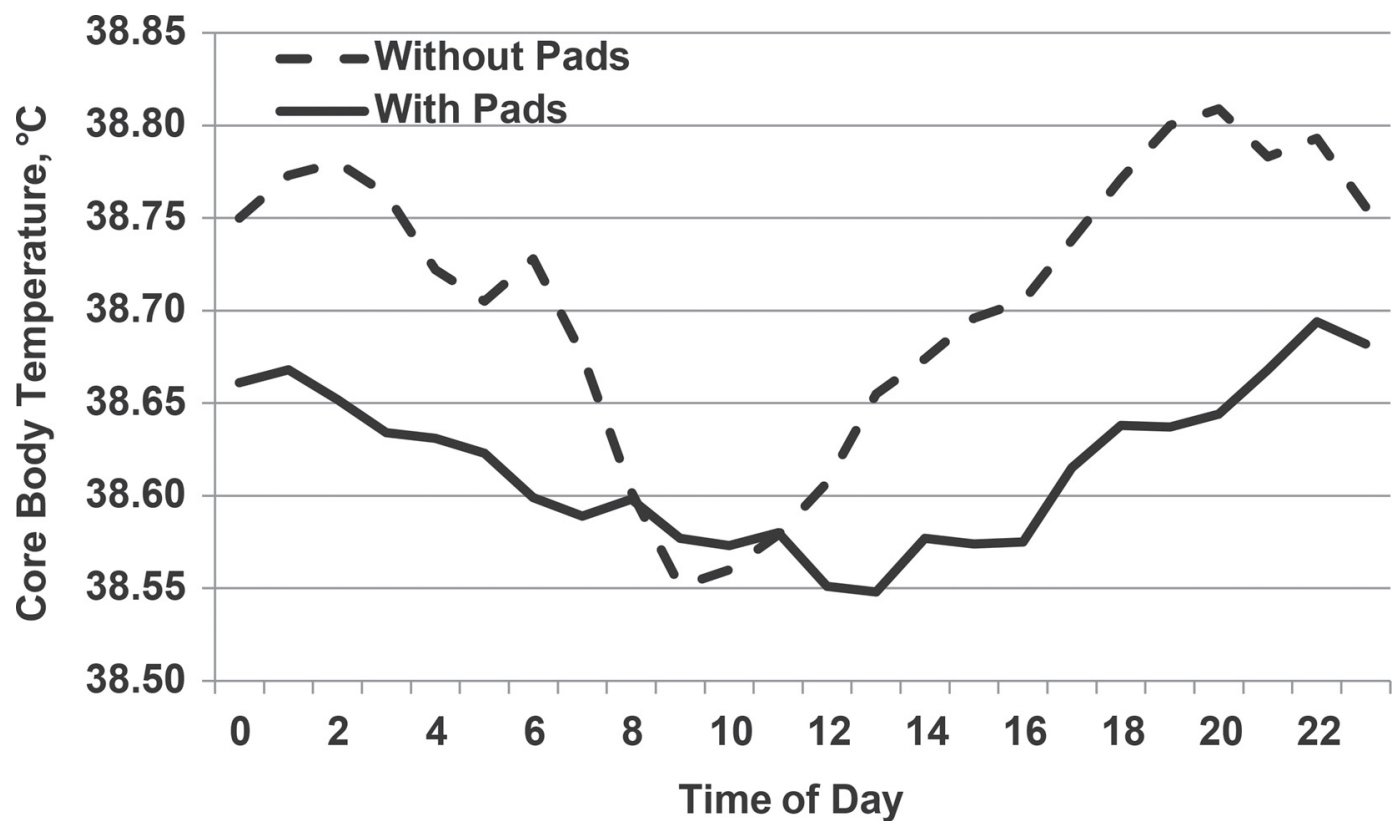

Figure 3. Effect of cross ventilation with or without evaporative pads on core body temperature of lactating dairy cows in northern Midwest United States. Treatment $(P<0.04 ; \mathrm{SEM}=0.03)$ and treatment $\times$ hour $(P<0.0001 ; \mathrm{SEM}=0.03)$ effects were observed. 
Table 2. Effect of cross ventilation with or without evaporative pads on categorical core body temperature (CBT) and standing behavior of lactating dairy cows in northern Midwest United States ${ }^{1}$

\begin{tabular}{|c|c|c|c|c|}
\hline \multirow[b]{2}{*}{ Item } & \multicolumn{2}{|c|}{ Treatment } & \multirow[b]{2}{*}{ SEM } & \multirow[b]{2}{*}{$P$-value } \\
\hline & Without pads & With pads & & \\
\hline \multicolumn{5}{|c|}{ Time (min/d) with CBT: } \\
\hline$<38.6^{\circ} \mathrm{C}$ & 598.4 & 768.1 & 54.7 & 0.03 \\
\hline$>38.6$ & 841.6 & 671.9 & 54.7 & 0.03 \\
\hline$>38.9$ & 365.0 & 167.4 & 51.6 & 0.01 \\
\hline$>39.2$ & 140.5 & 33.2 & 32.2 & 0.02 \\
\hline$>39.4$ & 51.9 & 8.1 & 17.1 & 0.07 \\
\hline$>39.7$ & 16.4 & 2.3 & 6.0 & 0.10 \\
\hline \multicolumn{5}{|c|}{ Standing time $(\mathrm{min} / \mathrm{d})$ with CBT: } \\
\hline$<38.6^{\circ} \mathrm{C}$ & 329.7 & 415.0 & 39.1 & 0.13 \\
\hline$>38.6$ & 426.8 & 335.9 & 35.4 & 0.07 \\
\hline$>38.9$ & 182.2 & 87.9 & 34.5 & 0.06 \\
\hline$>39.2$ & 74.7 & 21.9 & 21.2 & 0.08 \\
\hline$>39.4$ & 29.5 & 6.2 & 11.0 & 0.14 \\
\hline$>39.7$ & 10.5 & 2.0 & 4.0 & 0.14 \\
\hline
\end{tabular}

${ }^{1} \mathrm{n}=112 ; 14$ cows/pen; 8 pens/treatment. Nine days of data were collected.

Previous research has shown that cows are negatively affected by heat stress (Johnson et al., 1963; Rhoads et al., 2009). Core body temperature and lying bouts are good indicators of the severity of heat stress in cows. One result of an imbalance between heat energy produced by the animal and amount of heat dissipated is an increase in CBT as a physiologic response of dairy cows (Ortiz et al., 2010). In addition, a decrease in lying time, lying bouts, or a combination of both has been correlated with increased heat stress and can be physiologically problematic to the dairy cow (Hillman et al., 2005; Cook et al., 2007). The magnitude of heat stress in the current trial, although not severe, was still strong enough to detect a tendency of differing lying behavior between EP and NP cows.

Healthy dairy cattle typically maintain 12 to $13 \mathrm{~h} / \mathrm{d}$ of lying time (Jensen et al., 2005; Gomez and Cook, 2010). Cook et al. (2007) found that time spent standing increased from 2.6 to $4.5 \mathrm{~h} / \mathrm{d}$ from the coolest to the warmest sessions and that the maximum observed mean lying time was only $10.9 \mathrm{~h} / \mathrm{d}$. The relationship between CBT and standing behavior can be seen in Table 2, in which NP cows with $\mathrm{CBT}>38.6^{\circ} \mathrm{C}$ tended to stand $1.5 \mathrm{~h}$ longer than cows exposed to evaporative cooling.

In conclusion, a decrease in CBT was observed when cows had access to evaporative pads. However, evaporative cooling did not significantly alter lying behavior. These results must be evaluated in light of the fact that treatments were not perfectly balanced for stocking density, and ambient conditions did not induce acute heat stress during this study. Additional work under more severe heat stress conditions is recommended to evaluate effects of cow cooling on lying time.

\section{ACKNOWLEDGMENTS}

The authors thank M. A. G. von Keyserlingk of the University of British Columbia (Vancouver, BC, Canada) and K. Ito and C. R. Mullins of Kansas State University (Manhattan) for help in the design and conduct of the study. A special appreciation goes to Riverview LLP (Morris, MN) for its economic support of the development of this project.

\section{REFERENCES}

Collier, R. J., G. E. Dahl, and M. J. VanBaale. 2006. Major advances associated with environmental effects on dairy cattle. J. Dairy Sci. 89:1244-1253.

Cook, N. B., R. L. Mentink, T. B. Bennett, and K. Burgi. 2007. The effect of heat stress and lameness on time budgets of lactating dairy cows. J. Dairy Sci. 90:1674-1682.

Cooper, M. D., D. R. Arney, and C. J. C. Phillips. 2008. The effect of temporary deprivation of lying and feeding on the behaviour and production of lactating dairy cows. Animal 2:275-283.

Dukes, H. H. 1947. The Physiology of Domestic Animals. 6th ed. Comstock Publishing Company Inc., Ithaca, NY.

Fregonesi, J. A., and J. D. Leaver. 2001. Behaviour, performance and health indicators of welfare for dairy cows housed in strawyard or cubicle systems. Livest. Prod. Sci. 68:205-216.

Gomez, A., and N. B. Cook. 2010. Time budgets of lactating dairy cattle in commercial freestall herds. J. Dairy Sci. 93:5772-5781.

Hillman, P. E., C. N. Lee, and S. T. Willard. 2005. Thermoregulatory responses associated with lying and standing in heat-stressed dairy cows. Trans. ASAE 48:795-801.

Igono, M. O., B. J. Steevens, M. D. Shanklin, and H. D. Johnson. 1985. Spray cooling effects on milk production, milk, and rectal temperatures of cows during a moderate temperate summer season. J. Dairy Sci. 68:979-985.

Ito, K., M. A. G. von Keyserlingk, S. J. LeBlanc, and D. M. Weary. 2010. Lying behavior as an indicator of lameness in dairy cows. J. Dairy Sci. 93:3553-3560.

Ito, K., D. M. Weary, and M. A. G. von Keyserlingk. 2009. Lying behavior: Assessing within- and between-herd variation in free-stallhoused dairy cows. J. Dairy Sci. 92:4412-4420. 
Jensen, M. B., L. J. Pedersen, and L. Munksgaard. 2005. The effect of reward duration on demand functions for rest in dairy heifers and lying requirements as measured by demand functions. Appl. Anim. Behav. Sci. 90:207-217.

Johnson, H. D., A. C. Ragsdale, I. L. Berry, and M. D. Shanklin. 1963. Temperature-humidity effects including influence of acclimation in feed and water consumption of Holstein cattle. Missouri Agric. Exp. Sta. Res. Bul. 846. University of Missouri, Columbia.

Liao, C., and K. Chiu. 2002. Wind tunnel modeling the system performance of alternative evaporative cooling pads in Taiwan region. Build. Environ. 37:177-187.

Munksgaard, L., and P. Lovendahl. 1993. Effects of social and physical stressors on growth hormone levels in dairy cows. Can. J. Anim. Sci. 73:847-853.

Munksgaard, L., and H. B. Simonsen. 1996. Behavioral and pituitary adrenal-axis responses of dairy cows to social isolation and deprivation of lying down. J. Anim. Sci. 74:769-778.

Ortiz, X. A., J. F. Smith, B. J. Bradford, J. P. Harner, and A. Oddy. 2010. Effects of running time of a cattle-cooling system on core body temperature of cows on dairy farms in an arid environment. J. Dairy Sci. 93:4949-4954.

Ortiz, X. A., J. F. Smith, B. J. Bradford, J. P. Harner, and A. Oddy 2011. Effect of complementation of cattle cooling systems with feedline soakers on lactating dairy cows in a desert environment. J. Dairy Sci. 94:1026-1031.
Overton, M. W., W. M. Sischo, G. D. Temple, and D. A. Moore. 2002. Using time-lapse video photography to assess dairy cattle lying behavior in a free-stall barn. J. Dairy Sci. 85:2407-2413.

Ravagnolo, O., and I. Misztal. 2000. Genetic component of heat stress in dairy cattle, parameter estimation. J. Dairy Sci. 83:2126-2130.

Rhoads, M. L., R. P. Rhoads, M. J. VanBaale, R. J. Collier, S. R. Sanders, W. J. Weber, B. A. Crooker, and L. H. Baumgard. 2009. Effects of heat stress and plane of nutrition on lactating Holstein cows: I. Production, metabolism, and aspects of circulating somatotropin. J. Dairy Sci. 92:1986-1997.

Scharf, B., D. Liu, J. M. Leath, S. A. Kelly, T. X. Nguyen, Y. Shi, M. Schrader, G. D. Martin, P. A. Eichen, and D. E. Spiers. 2014. Monetary impact of heat stress on dairy and beef industries in the US. J. Dairy Sci. 97(E. Suppl. 1):521. (Abstr.)

Singh, S. S., W. R. Ward, K. Lautenbach, and R. D. Murray. 1993. Behaviour of lame and normal dairy cows in cubicles and in a straw yard. Vet. Rec. 133:204-208.

St-Pierre, N. R., B. Cobanov, and G. Schnitkey. 2003. Economic losses from heat stress by us livestock industries. J. Dairy Sci. 86:E52E77.

Umphrey, J. E., B. R. Moss, C. J. Wilcox, and H. H. Van Horn. 2001. Interrelationships in lactating Holsteins of rectal and skin temperatures, milk yield and composition, dry matter intake, body weight, and feed efficiency in summer in Alabama. J. Dairy Sci. $84: 2680-2685$. 